\title{
Forms of Capital and Career Benefits of the MBA in
}

\section{China and the UK}

\author{
Afam Ituma \\ Brunel University \\ Uxbridge, UB8 3PH \\ Email: Afam.ituma@brunel.ac.uk \\ Ruth Simpson \\ Brunel University \\ Uxbridge, UB8 3PH \\ Email: r.simpson@brunel.ac.uk \\ Xiangping Bo \\ Hunan University \\ Hunan, China \\ Email: boxiangping@yahoo.com.cn \\ Adrian Woods \\ Brunel University \\ Uxbridge UB8 3PH \\ Email: Adrian.woods@brunel.ac.uk \\ Jane Sturges \\ Management School \\ Kings College \\ London SE1 9NH \\ Email: Jane.sturges@kcl.ac.uk
}




\title{
Forms of Capital and Career Benefits of the MBA in China and the UK
}

\begin{abstract}
This paper sets out the results of a research project which compares benefits from the MBA in China and the UK. Drawing on and modifying Bourdieu's forms of capital theory, it highlights areas of commonality and difference. In particular it demonstrates that some forms of capital (e.g. institutional, social) transcend national boundaries and are equally valued in both contexts. Significant differences emerge within categories of cultural capital with Chinese respondents placing a higher value on more technical and UK respondents placing a higher value on personal and interpersonal skill components. Implications for the transferability of Western based management education to China are evaluated and discussed.
\end{abstract}

Key words: China, MBA, Management 


\section{Introduction}

This paper explores the benefits from the MBA for Chinese graduates who studied in China and makes some comparisons with non-Chinese graduates from the UK. The unprecedented growth in China's economy since market reforms in the early 1980s has been matched by an increasing demand for management education. The Chinese economy, now the fourth largest in the world, has grown five fold in the last 20 years to reach 20.94 trillion yuan (\$2.68 trillion) GDP, incomes have quadrupled and expectations are that the economy will continue to grow at approximately $10 \%$ per year (National Bureau of Statistics of China, 2007). This level of development together with subsequent changes in systems of corporate governance from one centrally planned (directed and controlled by the state) to ones based on market principles, has highlighted key shortages of managerial talent (Zhang, et al., 2001; Lockett, 1988). More specifically, Bai and Enderwick (2005) note that the restructuring of the economy and resulting efficiency gains have resulted in critical shortages of individuals with appropriate management skills to manage its 400,000 state owned enterprises, 300,000 joint ventures and 200,000 township enterprises. Perhaps in response, MBA take-up both at home and abroad, has proliferated. Over 160 MBA programmes are now delivered in more than 80 institutions in China and the number of MBA students has increased from 2,400 in 1997 to 8,000 in 2006 (China Business Review, 2004). The Shanghai Education Commission estimates China will need 37,500 MBA graduates each year and well over I.5million MBAs over the next 10years to sustain its booming economy (Jelen and Alon, 2005). However, despite the popularity of the MBA, it is still in its infancy in China (Shi, 2000). Accordingly, while there has been some substantial research on MBA outcomes in the UK and US (e.g. AMBA, 2005; Catalyst, 2000), little is known about the perceived benefits from the course, in the form of skill enhancement and related outcomes, in China. Drawing on and modifying Bourdieu's (1997) forms of capital theory, this paper accordingly explores these 
outcomes for Chinese nationals who have studied in China and makes some comparisons with benefits for non-Chinese graduates who studied in the UK.

\section{The MBA in China and the UK}

MBA programs were introduced to China in the early 1980's during the start of reform programs. Prior to that time, Soviet style management education was aimed at training cadres to fulfil administrative posts within state owned enterprises (SOE's). As such, management education was heavily influenced by a legacy of technical, discipline based education as well as planning techniques and production control - deemed suitable for effective administration at the time. Management education in China is also underpinned by the Confucianism ideology which emphasises hierarchy, respect for age, harmonious relationship and the preservation of 'face'. In such a context, as Alon and McIntyre (2005) have argued, students tend to develop mastery of principles through rote learning by assimilating knowledge rather than through critical analysis.

In China, early MBA programmes were conducted jointly with Western based institutions and reflected dominant beliefs that management as well as management education were founded on general universal principles and techniques that could be applied in any context (Clegg et al, 2005). Western universities therefore provided the curricula, textbooks and other teaching materials and courses were mainly delivered in English. By the 1990s, Chinese owned programmes were introduced on an experimental basis and carefully controlled by the Academic Degree Committee (ADC), the highest ranked government authority supervising the award of academic degrees by universities in China. Since then, there has been an increase in the number of universities offering accredited MBA programmes. Most of these MBAs were modelled on 
Western curricula and taught in a largely traditional way with, as Shi (2000) points out, a focus on technical details (e.g. production, $\mathrm{R} \& \mathrm{D}$, finance and engineering) to the neglect of behaviorally oriented and more culturally specific areas such as marketing strategy, training and HRM (McLean and Shi, 2000; Haight and Kwong, 2000). However, this trend is been revised with an increasing emphasis on the development of a hybrid approach which adapts Western management education style to suit the local Chinese context (Wong-MingJi et al,2005). A notable example is CEIBS (The Chinese European International Business School), a Shanghai university MBA programme which is taught in English and draws on a Western pedagogic approach but which has been customized to the Chinese business and management environment.

Overall, the general rise of commercial activities together with the growth of joint ventures and MNCs has had key implications for management education. Firstly, it has led to a severe shortage of managerial talent (Tjosvold and Ding, 2001; Tang and Ward, 2004; Li, et al., 2005; Bai and Enderwick,2005) with the demand for qualified managerial personnel outstripping supply. In particular, the development of managerial practices suitable for an international environment is a key issue for Chinese owned enterprises. Secondly, careers in China are becoming increasingly westernised in that there is increasingly reliance on personal capabilities rather than on the previous party allegiance for advancement and an emphasis on skill mobility and development as individuals move from job to job (Lee, 1999; Fan, 2000; Zhang, et al., 2001). In this respect, Chinese management education may still be lacking in the development of these transferable skills. Thirdly, the need to compete internationally and understand global markets, as well as the need to manage key relationships inside and outside the organization, has led to a demand for an understanding of organizational behaviour, strategy and marketing as well as for the development of personal and interpersonal skills. 
The MBA has a longer history in the UK, with rapid growth following the Constable and McCormick (1987) and the Handy (1987) reports, both of which highlighted deficiencies in UK management education and called for an expansion in the provision of management education (the number of MBA graduates accordingly rose from 1,200 in 1986 to 10,000 in 2000). More recently, there have been debates similar to those outlined above concerning the relevance of MBA programs to the modern business world. Critics have suggested that MBA in both North America and the UK focuses too much on the functions of management at the expense of the practice of managing with associated interpersonal and leadership skills (Kretovics, 1999; Mintzberg and Gosling, 2002; Simpson et al, 2005).

Therefore, while China is at a different stage of economic development and has its own specific political and cultural heritage based on communism (product orientation, state ownership and planning) and Confucianism (harmony, hierarchy, social obligations), it is possible that it shares with the UK an under-investment in some management skills. This gap, however, is likely to include a broader range of competencies. Marketing and HRM, for example, have a strong Western tradition but are relatively new in Communist China where production under a Marxist tradition has taken precedence over distribution and where many of the functions associated with HRM (training, development, reward systems) have in the past been left to the state. This paper accordingly sets out to unravel the different outcomes from the MBA in each context and to explore the nature of benefits gained by graduates who studied in China, drawing comparisons with those gained by non-Chinese students within the UK. 


\section{Investing in the MBA: Forms of Capital Theory}

In addition to outcomes in the form of monetary gain, Bourdieu (1984; 1997) suggests investment in education can comprise cultural capital (an individual's knowledge about the products of artistic or intellectual traditions which help to distinguish the holder of that knowledge from others) and social capital (made up of connections).

\section{Cultural capital}

Cultural capital is divided into embodied capital, which captures long lasting 'dispositions of the body and mind' through for example the acquisition of skills and aptitudes, and institutionalised capital, in which cultural capital is objectified (institutionalised) in the qualification. In this latter respect, the qualification is seen as a 'certificate of cultural competence' which confers a value on the holder and confirms or legitimises the supposed possession of skills and knowledge. Accordingly, within the category of cultural capital, the MBA experience can develop capabilities in the form of embodied capital and the MBA qualification can comprise a badge of recognition in the form of institutional capital to the holder of the degree. Bourdieu views such capital as 'symbolic' in the sense that it confers legitimacy and prestige on the holder and allows him/her to command a status based upon inferences of special expertise. The MBA accordingly symbolises a certain positioning in the managerial world. The 'symbolic efficacy of cultural capital' (e.g. the symbol of the MBA as badge of distinction) thus enables holders to distinguish themselves from others (i.e. those who do not hold the degree). Cultural capital therefore captures skills and knowledge gained from education that are 'embodied' in the sense that they are inextricably tied to the body or mind of the person concerned.

Taking a rather broader view of cultural competence as a set of cross-cultural skills and competencies that enable individuals to work effectively in cross-cultural situations (Cross et al, 1989), scholars have argued for the importance of such capital in the work context (e.g. Isaac \& Benjamin, 1991; Davis, 1997; Barrera \& Kramer, 1997; Lynch \& Hanson, 1998). Following from this perspective, Reid and Reid (2006) argue that cultural competence is a developmental process that occurs along a continuum rather than an end-state and as such an individual can never fully 
achieve cultural competence. Moreover, individuals will often be exposed to different cultural settings which will involve demonstration of different sets of skills in different circumstance. They suggest that what is imperative is for individuals to value diversity, develop the capacity for cultural self assessment, demonstrate sensitivity to the dynamics inherent when cultures interact and adapt practices to suit specific cultural situations. From an organisational perspective, research suggests that organisations that demonstrate cultural competence achieve better outcomes which include clients' satisfaction and service improvement (see for example, Wade and Bernstein, 1991).

Within the context of an MBA, Hay's (2006) UK study provides evidence that an MBA can enhance cultural competence. In essence an MBA can be seen to confer a value upon the holder which confirms or legitimises the supposed possession of cultural competence skills which equips an individual with the capability to function within cross-cultural environment. This kind of skill is increasingly valued in an international business environment where individuals are expected to relate effectively with people from diverse cultural background.

All this points to the importance of cultural capital and cultural competence to managers at work that may go beyond Bourdieu's original conceptualisation. In a study of MBA outcomes, Robinson (2005) for example argues for a more 'nuanced' approach in order to capture the range of skills and competencies so acquired. Simpson et al (2005) for example, distinguish between course related, functional skills which are based on the subject matter of the modules/units taken (e.g. financial management, data analysis, business planning) and other personal and interpersonal skills which may accrue in a more 'ad hoc' manner through the experience of studying on and working for an MBA. Personal skills are taken to include that part of self development which concerns how the individual sees him or her self (e.g. confidence, self belief) while interpersonal skills include those capabilities that enhance working relationships with others (e.g. leadership, communication, team-working). Within the broad category of embodied cultural capital we accordingly distinguish between 'functional capital' i.e. functional course related skills; 'personal capital' i.e. perceptions of and belief in self; and 'interpersonal capital' i.e. those skills that enhance interactions with others in different contexts. 


\section{Social Capital}

Social capital refers to the resources that accrue from group membership. Bourdieu and Wacquant (1992) defines it as the "sum of the resources, actual or virtual, that accrue to an individual or group by virtue of possessing a durable network of more or less institutionalised relationship of mutual acquaintance and recognition" (p.119). Coleman (1990) argues that social capital makes possible the achievement of economic and non-economic outcomes which would not otherwise have been feasible while Putnam (1993) views social capital as a factor of production in the sense that it can be used as a mechanism for creating sustainable economic development. He argues that social capital can improve the efficiency by aiding coordinated action, promoting business networking, joint ventures, faster information flows and more agile transactions. This view is supported by research undertaken by Guiso et al (2004) in different regions of Italy. The findings of their research shows that Italian regions characterized by high social capital (trust, reciprocity, civic engagement) were more economically developed than areas with less social capital (unwillingness to trust and engage).

At an individual level, research suggests that mangers with rich social capital tend to receive more positive evaluations (Burt et al, 1998; Mehra and Kildnff, 1999), earlier promotion (Podolny and Baron, 1997), higher compensation (Bielby and Bielby, 1999) and higher performance (Geletkanycz and Hambrick, 1997). Social capital has also been found to lead to higher probability of innovation and learning for organisations (Stuart and Podolny, 1999). In the context of MBA, being part of the so-called MBA 'elite' (Watson, 2001) can give access to networks from associations with fellow students, staff and other key individuals. As Bourdieu points out, these associations are often based on friendships, respect and reciprocity. These networks, forged during an MBA, have been found to be important in helping to further an individual's career (Sturges et al, 2003) and can constitute a potential pool of knowledge and expertise.

\section{Applying Forms of Capital to MBA Outcomes in China and the UK}

\section{$\underline{\text { Functional Capital }}$}

As we have seen above, management development in China continues to have a technical focus 
at the expense of behaviorally oriented and consumer focused area (McLean and Shi, 2000; Haight and Kwong, 2000). As Fan (1998) points out, both strategic management and marketing, while needed in China, may be least understood because many managers have had little experience of operating in a competitive market. In essence, while organizational behaviour has been viewed with suspicion in China (Fan, 1998), it occupies a secure position within the UK based MBA. These functions can be seen to have 'hard' (i.e. technical) and 'soft' (i.e. social or behavioural) elements (Fan, 1998). On this basis, production, R\&D, innovation, finance and accounting can be seen to have more hard elements while organizational behaviour, marketing and HRM may be viewed as largely soft (ibid). As Chinese managers are more likely than UK managers to come from a technical or engineering background (Tang and Ward, 2003), they may assimilate such know-how more easily. By the same token, and for some of the reasons outlined earlier, they may be less comfortable with softer areas.

Thus proposition 1a:

MBA graduates in China will gain significantly more than MBA graduates in the UK in terms of the level of hard functional capital acquired from the course

and

proposition 1b:

MBA graduates in the UK will gain significantly more than MBA graduates in China in terms of the level of soft functional capital acquired from the course

$\underline{\text { Personal Capital }}$

Personal capital has been taken to refer to self- belief, autonomy and confidence in self. Several Western based studies have illustrated the importance MBA graduates attach to increased confidence as an outcome from the course - as well as greater self belief and autonomy (Simpson 
et al, 2005; Sturges et al, 2003; Grey, 2002). However, there are likely to be cultural variations in the extent to which this is an outcome from the MBA. In China, the importance placed on hierarchy and a respect for age (Lockett, 1988) together with a high power distance with subordinates compared to other cultures (Hofstede, 1980) has meant that Chinese middle managers in particular have less decision making powers than in Western enterprises. As Ahlstrom et al (2001) argue, Chinese managers tend to be risk averse and often lack confidence to speak out, to rely on their own judgments, to make independent decisions or to suggest new ideas. Studies on gender differences in MBA outcomes (e.g. Simpson, 2000a; 2000b) suggest that women, who lack confidence prior to the course, perceive greater gains in this respect. On the same basis, if they similarly lack confidence, Chinese graduates may perceive more gains from personal capital in comparison with those in the UK

Thus, proposition 2:

MBA graduates in China will gain significantly more than MBA graduates in the UK in terms of the level of personal capital acquired from the course

\section{Interpersonal Capital}

Interpersonal capital has been taken to refer to interpersonal skills gained from education that enhance the quality of interactions with others in different contexts. In this respect, Western culture is based more on individualism with a focus on self (Lockett, 1988; Tang and Ward, 2004) while Chinese culture has an orientation towards relationships, particularly towards maintaining strong bonds and harmony (Shi, 2001). Personal connections (guanxi) play an important role in Chinese business together with the need for abilities pertaining to the successful management of such relationships. Together with their more technical orientation towards management education, 
and the likely development of these skills outside the course, MBA graduates in China may therefore perceive fewer benefits from interpersonal capital. By contrast, Western based studies (e.g. Hilgert, 1998) have demonstrated a high value placed by graduates on such outcomes from the course.

Thus, proposition 3:

MBA graduates in the UK will gain significantly more than MBA graduates in China in terms of the level of interpersonal capital acquired from the course

\section{$\underline{\text { Social Capital }}$}

Social capital relates to resources from connections and from group membership. The above discussion points to the high value given to social capital, in the form of relationships and connections, to Chinese managers and to Chinese business as a whole.

Thus, proposition 4:

MBA graduates in China will gain significantly more than MBA graduates in the UK in terms of the level of social capital acquired from the course

\section{$\underline{\text { Institutional Capital }}$}

Institutional capital is that part of cultural capital which confers, through the qualification, a badge of recognition. As Bourdieu argues, such capital is 'symbolic' in the sense that it confers legitimacy and prestige on the holder and allows him/her to command a status based upon inferences of special expertise. The MBA accordingly symbolises a certain positioning in the managerial world and enables the holder to distinguish him/herself from those who do not hold the degree. Lockett (1988) argues that Chinese attach more importance to attaining a certain position and being recognized by others than the Westerners. In other words, the drive to acquire status and prestige may be more compelling in China, than in the UK.

Thus, proposition 5: 
MBA graduates in China will gain significantly more than MBA graduates in the UK in terms of the level of institutional capital acquired from the course

\section{Research Method}

The Sample

The Chinese data was drawn from five schools across China. Two schools were local in that they were run solely by PRC institutions while the other three were run jointly by a PRC and a foreign based institution. The UK data was drawn from a single well- established business school in the South-East of England. Data was drawn from a sample of 272 MBA graduates, evenly divided by country (i.e. 136 each in China and the UK). In both countries, the majority (nearly two thirds) were aged between 25 and 34. The UK sample tended to have a higher level of qualification prior to their MBA. While the UK sample was evenly spread across disciplinary areas, few of the Chinese sample had an Arts/Humanities background, having either a background in Economics and Business Studies or Science and Engineering. In both countries most graduates financed their MBA studies from their own resources. While the majority of the UK sample studied for their MBA full time, the Chinese sample studied almost equally across different modes (e.g. full time, part time day, part time evening).

At the time of the survey, all graduates had been in the labour market for at least a year with their MBA qualification. One quarter of the Chinese sample worked in the public (state) sector, one fifth in joint ventures and $13 \%$ in 'other private sector'. In the UK, the majority were located in this latter category $(85 \%)$ with most of the remainder in the public sector. There were no significant differences between the two samples in terms of management roles at the point of entry to the MBA.

\section{The Survey}


The survey was conducted in three stages. In stage one, a Chinese version of the questionnaire was prepared and evaluated by the Chinese project partners for validity and reliability of measures within their specific socio-cultural context and was modified accordingly. In stage two, after the final version of the research instruments had been established, one hundred and twenty questionnaires were sent to MBA alumni via two participating local universities in Southern China. From this, 55 were returned, representing a response rate of $45.8 \%$. In stage three, the questionnaire was put onto a website and emailed to Chinese alumni through partner universities. A further 81 responses were received (it was not possible to ascertain the response rate through this method).

The questionnaire was divided into two sections. The first section focused on demographic profile of the respondents. The second section explored perceived skills and benefits from the course. For all items, perceptions of benefits and outcomes from the MBA were measured on a 7 point Likert type scales (from 1: strongly agree to 7: strongly disagree). This length of scale was adopted in order to overcome methodological problems associated with an identified reluctance on the part of Chinese respondents to choose items at extremes and a tendency to concentrate their choices on the middle range (Cheng and Owen, 1997). The 7-point scale can go someway to address this problem by allowing a greater degree of discrimination between the middle and outer ranges to take place.

\section{The Measures}

Measures of career outcomes and other benefits drew on the successful methodology adopted in a similar cross national study in Canada and the UK (Simpson et al, 2005; Sturges et al, 2003). As discussed above, some items were modified to accommodate the specific set of cultural 
conditions in China. Scales for each type of capital (cultural, social) were created by adding items together. Cronbach alpha statistics show that all the scale reliabilities are above the 0.7 level (see below) which Nunnaly (1978) and Cronbach (1951) suggest as acceptable for basic research. The F test was applied to each scale as appropriate for comparing means. The F test was used to test for significant differences in mean scores for each scale as between UK and China respondents.

Drawing on Fan's (1998) typology of skills, functional capital was measured through 'soft' subject based skills and knowledge (HRM, Marketing, Strategy, Leadership, Organizational Behavior. Cronbach alpha: 0.799) and 'hard' subject based skills and knowledge (Data Analysis, Information Technology, Operations, Quantitative Analysis and Finance. Cronbach alpha: 0.789). Personal capital was measured with items relating to perceptions of enhanced confidence, self belief and autonomy (Cronbach alpha: 0.914). Interpersonal capital was measured through items concerning effectiveness of interactions with others including cross cultural working (Cronbach alpha: 0.913). Institutional capital, that part of cultural capital that gives a badge of distinction upon the owner, was measured by items capturing perceptions of enhanced credibility and of respect emanating from the qualification (Cronbach alpha: 0.725). Social capital was measured with two items (Cronbach alpha was therefore not calculated) relating to importance of networks and friendships (I make use of networks I have made through the MBA; I value the friendships made during the course). The F test was run on these two separate items. Due to the exploratory nature of the study, and along the lines suggested by Jacques and Kline (forthcoming), it was decided to report significance levels at $\alpha<.10$.

\section{Results}

Proposition 1a

MBA graduates in China will gain significantly more than MBA graduates in the UK in terms of the level of hard functional capital acquired from the course 
and

Proposition 1b

MBA graduates in the UK will gain significantly more than MBA graduates in China in terms of the level of soft functional capital acquired from the course

Proposition 1a was supported by the data. A significant difference emerged between China and the UK in terms of perceived benefits from hard functional capital, with Chinese respondents claiming to have gained more capital in this respect $(\mathrm{F}=5.002$; significance: 0.026$)$.

Proposition $1 \mathrm{~b}$ was not supported. There was no significant difference between China and the UK in terms of perceived benefits from 'soft' functional capital from the course - though on individual items significant differences emerged with respect to Marketing (significance: 0.010) and HRM (significance: 0.000) with Chinese respondents valuing these more highly.

\section{Proposition 2}

MBA graduates in the China will gain significantly more than MBA graduates in the UK in terms of the level of personal capital acquired from the course

Proposition 2 was not supported. There was a small but significant difference between China and the UK in terms of perceived benefits of personal capital from the MBA, with respondents from the UK claiming to have gained more capital in this respect $(F=3.350$; Significance: 0.068$)$.

\section{Proposition 3}

$M B A$ graduates in the UK will gain significantly more than MBA graduates in the UK in terms of the level of interpersonal capital acquired from the course

Proposition 3 was supported. Significant differences between China and the UK emerged in terms of perceived benefits from interpersonal capital from the MBA, with respondents from the UK claiming to have gained more capital in this respect. $(F=5.139$; Significance: 0.024$)$. 


\section{Proposition 4}

MBA graduates in China will gain significantly more than MBA graduates in the UK in terms of the level of social capital acquired from the course

Proposition 4 was not supported. There was no significant difference between China and the UK in terms of perceived benefits of social capital from the MBA.

\section{Proposition 5}

MBA graduates in China will gain significantly more than MBA graduates in the UK in terms of the level of social capital acquired from the course

Proposition 5 was not supported. There was no significant difference between China and the UK in terms of perceived benefits of institutional capital from the MBA

These results are summarized below

Tables 1 and 2 here

\section{Discussion}

This paper set out to explore the personal and career benefits of the MBA for Chinese graduates who studied in China, making comparisons with non-Chinese graduates from the UK. Results suggest significant differences between China and the UK in terms of perceptions of gains in the form of functional (hard) capital, personal capital and interpersonal capital.

Proposition 1a was supported in that a significant difference emerged in the perceptions of gains from 'hard' functional capital with Chinese respondents claiming more benefits in this respect. As we have seen, MBA programs in China have a more technical focus than in the West (Shi, 2000; Li et al, 2005), possibly reflective of the technical background of many managers and the higher value placed on technical expertise in managerial work (Tang and Ward, 2003). At the 
same time, these functional areas may be more easily transferable from one cultural context to another (Fan, 1998; Gamble, 2003), reducing problems of exchangeability of meanings from what is generally seen as a Western oriented management programme. This, together with the more technical orientation of Chinese MBA students, may mean they assimilate such knowledge more easily and that they place a high value on the outcomes. Financial analysis, for example, identified as the most highly valued aspect of hard functional capital by Chinese MBAs, is an area which may transfer more smoothly relative to other areas.

Proposition $1 \mathrm{~b}$ however was not supported in that, contrary to the expectation that the more technical focus of Chinese students would lead to a lesser perceptions of gains from 'soft' functional capital compared with the UK, there was no significant difference between China and the UK. In fact, on single items within this measure (Marketing, HRM) it was Chinese respondents who perceived greater gains in this respect. The increasing primacy given to Chinese to soft skills may reflect the growing orientation in the Chinese economy towards 'soft' functional areas which were either not considered important in the past (e.g. marketing) or which were left to the state (e.g. HRM) and which accordingly may make up a current 'skill gap' among aspiring managers. This finding is consistent with previous research which found that Chinese are generally good at hard skills and need to pay more attention to soft skills (Motorola Conference Presentation,1997). The MBA may therefore be helping, in the eyes of students, to close that gap.

Proposition 2 was not supported in that a significant difference between China and the UK emerged in terms of perceived benefits of personal capital from the MBA, with respondents from the UK claiming to have gained more capital in this respect. Personal capital has been taken to 
refer to self- belief, autonomy and confidence in self. The lower value placed by Chinese respondents on gains from personal capital may reflect the higher orientation of managers towards functional areas of management education discussed above. Furthermore, the more collectivist culture in China, with a lesser significance afforded to 'self', may not be conducive to a mindset that prioritizes personal development or reflections on self worth. A final explanation may be that the Chinese are in fact more confident (a key component of personal capital) and therefore do not see the same level of benefit as in the UK. There is some support for this view. In a cross cultural (US/China) study of differences in decision making, Yates and Lee (1996) found that the Chinese were more likely than those from the US to be overconfident in the decisions they took. While this may be surprising in the light of the negativity the Chinese attach to lack of modesty and self promotion (Tang and Ward, 2003), the authors hypothesize that the explanation lies in the more contentious, adversarial approach to settling arguments in the US, leading to a greater degree of caution. This compares with the more uncritical transfer of knowledge in China, which together with an avoidance of uncertainty and ambiguity (Littrell, 2005), may mean that overconfidence rests, in part, on less value being placed on promoting a questioning attitude.

Interestingly, confidence to voice opinions is the most highly valued outcome for Chinese respondents within this form of capital. As we have seen earlier, respect for hierarchy and age means managers in China often defer to authority (Lockett, 1988; Tang and Ward, 2004; Mclean and Shi, 2000) and are reluctant to speak out or suggest new ideas (Ahlstrom et al, 2001). This suggests that the MBA may have had an important effect in helping Chinese to voice their opinions. A Canadian based survey of MBAs found that gaining a voice was an important outcome for women, who (albeit for different reasons) felt they were often silent in work contexts 
prior to the course (Simpson et al, 2005).

Proposition 3 was supported in that respondents from the UK claimed to have gained more interpersonal capital. It was hypothesized that the orientation in China towards relationships and harmony (Lockett, 1988; Tang and Ward, 2004; Shi, 2001), where contracts often rely on personal connections as well as reciprocity and trust, would mean a greater level of skill development outside the course, skills which they have internalized as a 'normal' part of working life. This may be reflected for example in a greater level of 'cultural competence' in terms of managing relationships inside and outside the organization. Highlighting the importance of the ability to maintain harmonious relationships, Tang and Ward (2003) found that such competence was a key factor in promotion decisions for Chinese managers and that the cementing of their network of personal relationships was seen as central to carrying out their work and to managing their career. Moreover, together with the greater orientation of Chinese students and Chinese based MBA programs towards technical and functional aspects of management, this may not be viewed as a priority outcome from a management development program. By contrast, the growing awareness of the importance of the development of interpersonal skills in management (CIPD, 2005; Becker and Huselid, 1998) and in management education (Grey, 2002; Mintzberg and Gosling, 2002) may well be reflected in UK based programmes and may lead to a greater value placed by MBA students and graduates on these outcomes from the course.

In terms of propositions 4 and 5, no significant differences were evident from the data in terms of social or institutional capital. The lack of difference between China and the UK in terms of social capital may be surprising given the greater orientation in China towards maintaining networks and relationships. Similarly, while position and recognition are significant factors in China 
(Lockett, 1988) suggesting a greater priority may be given to the 'badge' of the MBA, there was no difference in how institutional capital was valued between China and the UK. This result is surprising given that the MBA is perceived widely in China as the most recognized and prestigious management degree (Micklethwait, 1996). Similarly, Western based work has also pointed to the significance of the MBA in developing networks and in conferring credibility to the manager in the workplace (Simpson, 2000a; Sturges et al, 2003), suggesting these outcomes can transcend cultural context. As Sturges et al (2003) point out, 'knowing who' is an important outcome from the MBA experience. Similarly, as Robinson (2005) has argued, the MBA has considerable value as institutional capital, serving to symbolize a positioning in the managerial world and to distinguish the holder, in a Bourdieuian sense, from non-holders of the degree. These factors may explain the similarity between China, which has traditionally placed value on these aspects, and the UK in terms of perceptions of benefits received.

\section{Conclusion}

This paper has made both an empirical and a theoretical contribution to our understanding of the benefits to be gained from an MBA. On an empirical level, and in the context of the enormous growth in Chinese management education both inside and outside China, it has provided unique cross-national data from China and the UK. Overall, results suggest that while there are no differences in perceived benefits from 'soft' functional, institutional and social capital, and while Chinese graduates place a higher value on hard functional capital, UK respondents perceive greater benefits from personal and interpersonal capital forms. This lends some support to the view that the nature of perceived outcomes can be affected by the perceived instrumentality of the learned skills or knowledge (Farr and Middlebrooks, 1990) as seen through the high value 
placed by Chinese respondents on hard functional capital and on the specific item of marketing as an outcome from the course. Moreover, perceptions of instrumentality may vary with UK respondents recognizing a wider range of benefits (e.g. personal and interpersonal capital) in this respect. On a theoretical level, it has adapted Bourdieu's forms of capital theory to the analysis of such outcomes and has included further subdivisions within cultural capital to produce a more comprehensive and nuanced account of returns from investment in education, such as a program leading to an MBA.

\section{Implications of the Research.}

The growth of management education in China as well as the increasing numbers of Chinese nationals who are undertaking MBA degrees in the West make some assessment of the outcomes from these qualifications and experiences an imperative if the quality and effectiveness of programs for all its students are to be sustained. As Li et al (2005) argue, greater globalization is likely to bring greater managerial complexity and risk and so requires 'more focused and polished' managerial skills (such as those encapsulated within 'cultural competence') to ensure necessary ‘brain circulation' and knowledge transfer. This paper has gone some way to address this hitherto research gap and has highlighted differences in the type and range of benefits identified in China and the UK. In particular the more technical orientation of programs in China and a possible functionalist orientation of students and staff may mean graduates are missing out on the development of important personal and interpersonal capabilities and that the 'eyeopening' experience commonly described as an outcome in the West (Hilgert, 1998; Simpson et al, 2005). This may also have implications for UK based programs which place greater emphasis on personal and interpersonal skill development but which may not be seen as an appropriate or highly valued form of management development by students from other cultural contexts. More broadly, these results can have implications outside these specific contexts. In the US, for 
example, as in the UK, a high value is placed on the acquisition of personal networks from the MBA (Kretovics, 1999). However, despite sharing some contextual characteristics with China, Japanese students have moved away from a functionalist orientation and have embraced social capital as an outcome from the MBA (Ishida, date). More research is required to further unpick the nature of relationship between benefits gained and cultural context. The research also suggests the need for business schools to consider all types of capital (both cultural and social) when preparing their curriculum.

At a more fundamental level, this research raises issues concerning the supposed transferability of management education and pedagogy that has been developed and grounded in the West (see Fan, 1998; Currie and Knights, 2003) and which is based on a Western notion of self. While, as Fan argues, an understanding of difference is important in overcoming barriers to transferring Western management practices to China, this project is predicated on a difference that 'normalises' the West and which has tendencies to view departures as deficient and thus to be homogenized (Westwood, 2001; Robinson, 2005). By linking key cultural factors specific to the Chinese context to a framework of capital returns, this research provides a greater understanding of difference which, rather than implicitly or explicitly signifying default, helps unpick some of the underlying factors contributing to variations in perceived outcomes from the MBA.

\section{Limitation of the Research}

This research has several limitations. Firstly, the UK data was drawn from one, albeit large and well established, MBA provider. Such a sample may well limit the generalizability of the findings beyond that specific research context. However, as Ibarra (1995) points out, small sample research can provide a foundation for and inform future work. Secondly, access difficulties meant the Chinese sample was drawn from local institutions and institutions that were 
run jointly by a PRC and a foreign based university. There was therefore some Western influence (beyond the broad rationale for the degree) in the content and implementation of the Chinese based programmes. This may have interfered with some of the results. Finally, an identified reluctance of Chinese respondents (Cheng and Owen, 1997) to choose items at the extremems of Likert scales may not have been fully overcome by a wider 7-point scale and may explain the more cautious nature of some of these results. However, despite these problems this research has gone some way to bridge the current research gap on outcomes of the MBA in China and the UK and as such can form the foundation for future research.

\section{References}

Ahlstrom, D., Bruton, G. and Chan, E. (2001) HRM of Foreign Firms in China: The Challenge of Managing Host Country Personnel, Business Horizons, 44 (3): 59-60

Association of MBAs (2005) Annual Report, AMBA

Becker, B. \& Huselid, M. (1998). High performance work systems and firm performance. Research in Personnel and Human Resource Management, 16: 53-101

Bourdieu, P. (1997) The Forms of Capital in A. H. Halsey, H. Lauders, P. Brown and A. Stuart Wells (eds) Education: Culture, Economy and Society, Oxford: Oxford University Press

Bourdieu, P. (1984) Distinction: A Social Critique of the Judgement of Taste, Cambridge, MA: Harvard University Press

Catalyst. (2000). Women and the MBA: gateway to opportunity. New York: Catalyst.

China Business Review (2004) The MBA Boom, January/February

Cheng, Y. and Owen, B. (1997) A Comparison of First Line Managers in the UK and China, 20th ISBA national Small Firms Policy and Research Conference, Belfast

Clegg, S., Gordon, R., Hermens, A., Kornberger, M., Rhodes, C. and Ross-Smith, A. (2005) Strange Brew: The MBA and Institutionalised Hypocritical Isomorphism in Management Education, Paper presented at the $4^{\text {th }}$ International Critical Management Studies Conference, Cambridge. 
Chartered Institute of Personnel and Development. (2005). Training and development: Annual survey report. London: CIPD

Constable, J. and McCormick, R. (1987) The Making of British Managers, BIM/CBI

Cronbach, L. J. (1951). "Coefficient alpha and the internal structure of test." Psychometrica 16: 297-334.

The Economist (2001) Enter the Dragon: Chinese Economic Power, March $10^{\text {th }}$ page 1

Fan, Y. (2000) The Transfer of Western Management to China, Management Learning 29 (2): 201-223

Farr, J. and Middlebrooks, C. (1990) Enhancing Motivation to Participate in professional Development, in Dublin S. (Ed) Maintaining Professional Competence, Jossey-Bass, San Francisco. Pp 199-213

Gamble, J. (2003) Transferring Human Resource Practices from the UK to China: The Limits and Potential for Convergence, International Journal of Human Resource Management, Vol 13 (3): $369-387$

Grey, C. (2002). What are business schools for? Journal of Management Education, 26: 496-511

Haight, T. and Kwong, K. (2000) Future of the MBA in China, Business Forum Vol 24 (1,2) 3336

Handy, C. (1987) The Making of Managers: A Report on Management Education Training and Development in the US, W. Germany, France, Japan and UK, MSC/NEDO/BIM

Hilgert, A. (1998). Professional development of women and the MBA, Journal of Management Development :17(9), 629-643

Hofstede, G. (1980) Culture's Consequences, Beverley Hills, CA: Sage

Ibarra, H. (1995). Race, opportunity and diversity of social circles in managerial networks, Academy of Management Journal, 38 (3), 673-703

Ip, O. (1999) A Case Study of Human Resource Practices in the People's Republic of China, International Journal of Employment Studies, 5(3) ??

Jacques, F. and Kline, T. (forthcoming) The Role of Self-differentiation in Predicting Emotional Intelligence and Leadership, International Journal of Work Organization and Emotion

Kretovics, M. (1999). Assessing the MBA What do our students learn?, Journal of Management Development:18 (2), 125-136 
Lee, J. (1999) Organizational Learning in China, Business Horizons 42 (1)

Li, M., Wong, Y. and Wang, Q. (2005) Management Education in Greater China Economy: Challenges and Tasks, in I. Alon and J. McIntyre (Eds) Business and Management Education in China, World Scientific

Littrell, R. (2005) Teaching Students from Confucian Cultures, in I. Alon and J. McIntyre (Eds) Business and Management Education in China, World Scientific.

Lockett, M. (1988) Chinese Culture and the Problems of Chinese Management, Organization Studies, Vol 9 (4): 475-96

McLean, G. and Shi, C. (2000) The Status of Training and Development in US-People Republic of China Joint Ventures, Journal of Transnational Management Development, vol 5 (4):

Mintzberg, H. \& Gosling, J. (2002). Reality programming for MBAs. Strategy and Business, $26(1), 28-31$

Mitroff, I. \& Churchman, C. (1992). Debate - MBA: is the traditional model doomed? Harvard Business Review, 70 (6): 128 - 40

Nunnally, J. (1978). Psychometric Theory. 2nd ed. New York, McGraw-Hill.

Robinson, S. (2005) Internationalisation and the MBA: A Hermeneutic Analysis of Students' Expectations, needs and Experiences, unpublished thesis, Lancaster

Shi, Y. (2000) A Status Report on MBA Education in China, International Journal of Education Reform, Vol 9 (4) 328-334

Shi, X. (2001) Antecedent Factors of International Business Negotiations in the China Context, Management International Review, 41: 163-187

Simpson, R. 2000a. Winners and losers: who benefits most from the MBA. Management Learning, 31(2), 46-54

Simpson, R. 2000b. A voyage of discovery or a fast track to success: men, women and the MBA. Journal of Management Development, 19: 764-782

Simpson, R., Sturges, J., Woods, A. \& Altman, Y. (2005). Gender age and the MBA: An analysis of extrinsic and intrinsic career benefits, Journal of Management Education 29: 218-247

Sturges, J., Simpson, R. \& Altman, Y. (2003). Capitalising on learning: an exploration of the MBA as a vehicle for developing career competencies. International Journal of Training and Development, 7 (1), 53-67

Tang. J. and Ward, A. (2003) The Changing Face of Chinese Management, London: Routledge 
Tjosvold, D and Ding, D. (2001) Management Training in China, Journal of Teaching in International Business Vol 12 (2): 53-76

Watson, T. (2001). Beyond managism: Negotiated narratives and critical management education in practice. British Journal of Management, 12: 385-396

Westwood, R. (2001) Appropriating the other in the Discourses of Comparative Management, in S. Linstead and R. Westwood (Eds) The Language of Organization 24-82 London: Sage

Yates, J. and Lee, J. (1996) Chinese Decision Making, in M. H. Bond (Ed) The Handbook of Chinese Psychology, Hong Kong: Oxford University press

Zhang, S., Wood, E. and Whiteley, A. (2001) The Challenge of Teaching HRM in China: Enabling Effective Management Education in the Context of Economic Reform, Journal of Teaching in International Business Vol 2: 77-89

Westwood, R. (2001) Appropriating the other in the Discourses of Comparative Management, in S. Linstead and R. Westwood (Eds) The Language of Organization 24-82 London: Sage

Table 1: Significant differences in capital acquired (mean figures)

\begin{tabular}{|l|l|l|l|l|}
\hline & China & UK & F statistic & Significance \\
\hline Economic capital & 12.4141 & 10.8182 & 6.886 & 0.009 \\
\hline $\begin{array}{l}\text { Hard functional } \\
\text { capital }\end{array}$ & 21.8629 & 23.8016 & 5.002 & 0.026 \\
\hline Personal capital & 29.8400 & 27.4688 & 3.350 & 0.068 \\
\hline $\begin{array}{l}\text { Interpersonal } \\
\text { capital }\end{array}$ & 24.0775 & 21.7576 & 5.139 & 0.024 \\
\hline
\end{tabular}

Table 2: Most Highly Valued Item within Forms of Capital (mean figures)

\begin{tabular}{|l|l|l|}
\hline Forms of Capital & China & UK \\
\hline Economic Capital & Job prospects (2.88) & Greater marketability (2.65) \\
\hline Hard functional capital & Financial analysis (2.92) & $\begin{array}{l}\text { Ability to analyze complex data } \\
(2.78)\end{array}$ \\
\hline Soft functional capital & Strategic management (2.47) & Strategic management (2.16) \\
\hline Personal Capital & $\begin{array}{l}\text { Confidence to voice opinions } \\
(2.70)\end{array}$ & Greater self awareness (2.34) \\
\hline Interpersonal capital & $\begin{array}{l}\text { Greater leadership abilities } \\
(2.50)\end{array}$ & $\begin{array}{l}\text { Greater leadership abilities } \\
(2.39)\end{array}$ \\
\hline Social Capital & $\begin{array}{l}\text { Friends made through the MBA } \\
(2.40)\end{array}$ & $\begin{array}{l}\text { Friends made through the MBA } \\
(2.11)\end{array}$ \\
\hline
\end{tabular}




\section{Word Count: 6867}

Although MBA experience has the potential to enhance community building (belonging, caring, mutual respect, team learning) and individual networking skills, empirical research on the impact of MBA on development of social capital has been mixed.. As yet, we do not know the impact of MBA on the development of social capital in the UK and China. However, it can be argued that the perceived impact of MBA on development of social capital will be context dependent in the sense that it will vary between institutions and between countries. It will be interesting to find out if UK and Chinese MBA graduates benefit equally from social capital. 